\title{
Intratumoral delivery of bortezomib: impact on survival in an intracranial glioma tumor model
}

\author{
Weijun Wang, MD, ${ }^{1}$ Hee-Yeon Cho, PhD, ${ }^{1}$ Rachel Rosenstein-Sisson, BFA, ${ }^{1}$ \\ Nagore I. Marín Ramos, PharmD, PhD, ${ }^{1}$ Ryan Price, BS, ${ }^{1}$ Kyle Hurth, MD, PhD, ${ }^{2}$ \\ Axel H. Schönthal, PhD, ${ }^{3}$ Florence M. Hofman, PhD, ${ }^{1,2}$ and Thomas C. Chen, MD, PhD',2 \\ Departments of ${ }^{1}$ Neurosurgery, ${ }^{2}$ Pathology, and ${ }^{3}$ Molecular Microbiology and Immunology, Keck School of Medicine, University of \\ Southern California, Los Angeles, California
}

\begin{abstract}
OBJECTIVE Glioblastoma (GBM) is the most prevalent and the most aggressive of primary brain tumors. There is currently no effective treatment for this tumor. The proteasome inhibitor bortezomib is effective for a variety of tumors, but not for GBM. The authors' goal was to demonstrate that bortezomib can be effective in the orthotopic GBM murine model if the appropriate method of drug delivery is used. In this study the Alzet mini-osmotic pump was used to bring the drug directly to the tumor in the brain, circumventing the blood-brain barrier; thus making bortezomib an effective treatment for GBM.
\end{abstract}

METHODS The 2 human glioma cell lines, U87 and U251, were labeled with luciferase and used in the subcutaneous and intracranial in vivo tumor models. Glioma cells were implanted subcutaneously into the right flank, or intracranially into the frontal cortex of athymic nude mice. Mice bearing intracranial glioma tumors were implanted with an Alzet miniosmotic pump containing different doses of bortezomib. The Alzet pumps were introduced directly into the tumor bed in the brain. Survival was documented for mice with intracranial tumors.

RESULTS Glioma cells were sensitive to bortezomib at nanomolar quantities in vitro. In the subcutaneous in vivo xenograft tumor model, bortezomib given intravenously was effective in reducing tumor progression. However, in the intracranial glioma model, bortezomib given systemically did not affect survival. By sharp contrast, animals treated with bortezomib intracranially at the tumor site exhibited significantly increased survival.

CONCLUSIONS Bypassing the blood-brain barrier by using the osmotic pump resulted in an increase in the efficacy of bortezomib for the treatment of intracranial tumors. Thus, the intratumoral administration of bortezomib into the cranial cavity is an effective approach for glioma therapy.

https://thejns.org/doi/abs/10.3171/2016.11.JNS161212

KEY WORDS glioma; bortezomib; Velcade; intracranial delivery; brain; mice; oncology

$\mathrm{G}$ LIOBLASTOMA (GBM) is the most prevalent and the most aggressive form of primary brain tumor. ${ }^{2}$ The current standard of care, which includes surgery, radiation, and chemotherapy, has increased survival to approximately 15 months from time of diagnosis; however, only $10 \%$ of patients survive at 5 years postsurgery. ${ }^{15}$ The key obstacle to treatment success is tumor recurrence and resistance to further chemotherapy. Repeated surgery and radiation are often not viable options. Therefore, it is critical to identify novel therapeutic approaches for the treatment of GBM.

In 2003 the FDA approved bortezomib (Velcade, Mil- lennium Pharma), the first proteasome inhibitor for therapeutic use..$^{19}$ This drug is currently used for the treatment of multiple myeloma and mantle cell lymphoma. ${ }^{5}$ The proteasome is an enzyme complex that is the major site of protein degradation, functioning to break down extraneous or abnormal intracellular proteins through selective destruction of these peptides. ${ }^{1,3,24}$ This activity is critical for normal cell cycling and a variety of other functions. Inhibition of proteasome activity leads to apoptosis. ${ }^{13}$ As a result of increased proapoptotic signaling and decreased prosurvival signaling, bortezomib effectively induces cells to undergo apoptosis. ${ }^{24}$ Proteasome inhibitors can cause

ABBREVIATIONS AMC = 7-amino-4-methylcoumarin; $\mathrm{BBB}=$ blood-brain barrier; $\mathrm{GBM}=$ glioblastoma; $\mathrm{IT}$ = intratumorally; IV = intravenously; MTT = monotetrazolium. SUBMITTED May 11, 2016. ACCEPTED November 7, 2016.

INCLUDE WHEN CITING Published online April 14, 2017; DOI: 10.3171/2016.11.JNS161212. 
cell death through the generation of reactive oxygen species, an increase in tumor necrosis factor-related apoptosis-inducing ligand (TRAIL) cell death through DR5 and Fas expression, and an increase in the proapoptotic Bcl-2 proteins Bim and Bad, as well as other cytotoxic mechanisms. ${ }^{11,13,20}$ Prior evidence suggests that proteasome inhibition may be selectively cytotoxic for glioma stem-like cells as compared with normal stem cells. ${ }^{9}$ Recent studies show that bortezomib induces cytotoxicity in glioma cells in vitro. ${ }^{25}$ However, the activity of bortezomib in intracranial tumor models is questionable. Studies have suggested that lack of bortezomib activity with systemic administration may be due to high levels of efflux transporters in the blood-brain barrier (BBB). ${ }^{22}$ Thus the route of bortezomib delivery plays an important role in the drug's efficacy.

Based on encouraging evidence that bortezomib has limited toxicity, ${ }^{10}$ we tested the effects of bortezomib on gliomas in vivo. When administered systemically, bortezomib effectively reduced tumor growth in the rodent subcutaneous tumor model but not in the intracranial tumors. However, when bortezomib was administered intratumorally (IT) in the orthotopic tumor model, this drug was effective. These experiments demonstrate that bortezomib can be used effectively against orthotopic tumors, but only if the mode of delivery bypasses the BBB and the drug is delivered directly to the intracranial tumor.

\section{Methods}

\section{Cell Culture and Therapeutic Drugs}

Human glioma cells (U87, U251, and LN229) were cultured in DMEM, supplemented with $10 \%$ fetal bovine serum and $1 \%$ penicillin-streptomycin, and incubated in $5 \% \mathrm{CO}_{2}$. Bortezomib (Velcade) was purchased from the University of Southern California/Norris Comprehensive Cancer Center pharmacy. Bortezomib has been approved by the FDA for clinical use. The sterile 14-day Alzet mini-osmotic pump (model 2002) was used in these experiments. The Alzet mini-osmotic pump has a reservoir volume of $200 \mu \mathrm{l}$ and a delivery rate of $0.5 \mu \mathrm{l} /$ hour. The brain infusion kit, which includes the pump and distribution tubing, was purchased from DURECT Corporation.

\section{The MTT Assay}

Glioma cells (5000 cells/well) were seeded in 96-well plates. After 24 hours, bortezomib was added to the cells at different concentrations, and the cells were incubated for 48 hours. The monotetrazolium (MTT) assay was performed according to the manufacturer's protocol (Calbiochem EMD, Millipore). Absorbance was measured using a microtiter plate reader (Molecular Devices) at $490 \mathrm{~nm}$. Percent viability was calculated relative to untreated control cells. All experiments were performed in triplicate.

\section{In Vivo Procedure for Subcutaneous Tumor Cell Implantation}

The animal protocol was approved by the institutional animal care and use committee of the University of Southern California. All mice were maintained in a pathogenfree environment throughout the experiment. For the subcutaneous tumor xenograft model, $5 \times 10^{5}$ human glioma cells (U87, U251, and LN229) suspended in a volume of 50 $\mu \mathrm{l}$ phosphate-buffered saline were implanted into the right flank of 30 athymic nude mice (Harlan, Inc.). Tumors were palpable approximately 2-3 weeks postimplantation. The animals were divided randomly into 5 groups of 6 mice, and treatment was initiated according to protocol.

\section{In Vivo Procedure for Intracranial Tumor Cell Implantation}

Briefly, athymic nude mice were anesthetized with ketamine and xylazine $(10 \mathrm{mg} / \mathrm{kg})$ and fixed into a stereotactic head frame (Harvard Apparatus). A 1.5-mm bur hole was drilled $1 \mathrm{~mm}$ anterior to the coronal suture on the right hemisphere and $2 \mathrm{~mm}$ lateral from the midline. A Hamilton syringe fixed onto the head frame was used to inject human glioma cells $\left(2 \times 10^{5}\right.$ cells $\left./ 5 \mu \mathrm{l}\right)$ into the right frontal lobe of the brain. The skin incision was then closed with 4-0 silk thread. The appropriate medications were provided to reduce pain.

\section{Procedure for Animal Imaging}

Seven to 10 days after tumor cell implantation, imaging was used to confirm brain tumor formation. Briefly, mice were anesthetized using $2 \%$ isoflurane gas and injected intravenously (IV) with $50 \mathrm{mg} / \mathrm{kg}$ of D-Luciferin (Perkin Elmer) and placed into the IVIS Spectrum (Caliper Life Sciences). Analysis was performed with Living Image software (Caliper Life Sciences), in which circular regions of interest drawn over the tumor site were used, and results were reported as total flux (photons/second). Based on total flux, animals were randomly divided into experimental groups.

\section{In Vivo Procedure for Alzet Mini-Osmotic Pump Implantation}

Once tumors were identified, approximately 7 days after intracranial tumor cell implantation, Alzet mini-osmotic pumps were filled with the desired dose of reagent and implanted. A plastic tube primed with the agent was used to connect the infusion kit to the brain. The assembled delivery system was stored at $4^{\circ} \mathrm{C}$ overnight before implantation. Bortezomib was delivered into the tumor using the Alzet mini-osmotic pumps.

To anchor the pump to the animal, an incision was made in the scalp alongside the previous surgical scar. The caudal edge of the incision was pulled, and the connective tissues were separated. Subsequently a subcutaneous tunnel was prepared. The Alzet mini-osmotic pump was pushed backward to adjust the location of the brain infusion kit directly above the hole in the skull that had been previously drilled for tumor cell implantation. The infusion kit (plastic tubing) was gently inserted into the formed tumor. The plastic platform end was fixed onto the skull by using instant super glue. The area around the skin incision was sterilized and sutured with 4-0 silk thread. The contents of the Alzet mini-osmotic pump were released into the tumor at a rate of $0.5 \mu \mathrm{l} / \mathrm{hour}$. The treatment groups (6 mice per group) were listed as the following: 1) pump-administered vehicle (saline); 2 ) bortezomib $(0.3 \mathrm{mg} / \mathrm{kg}=36 \mu \mathrm{g}$ in total) given by intravenous injection; 3) low-dose bortezomib $(0.003 \mathrm{mg} / \mathrm{kg}=0.36 \mu \mathrm{g}$ in total $)$ intracranial pump 
delivery; 4) medium-dose bortezomib $(0.01 \mathrm{mg} / \mathrm{kg}=1.2$ $\mu \mathrm{g}$ in total) intracranial pump delivery; and 5) high-dose bortezomib $(0.03 \mathrm{mg} / \mathrm{kg}=3.6 \mu \mathrm{g}$ in total $)$ intracranial pump delivery. In summary, bortezomib was administered for 14 days, either IV at $0.3 \mathrm{mg} / \mathrm{kg}$ twice weekly (total 4 injections in 14 days), or continuously into the intracranial tumor bed by using the Alzet mini-osmotic pump. After the treatment was completed (14 days), animals were left untreated until the appearance of neurological and behavioral abnormalities requiring euthanasia. Animals treated with vehicle received saline by Alzet mini-osmotic pump.

\section{Assay for 20 S Proteasome Activity}

Brain lysates were prepared by homogenization of tumor-bearing brains in phosphate-buffered saline. Supernatants were collected by centrifugation at $12,000 \mathrm{rpm}$ for 15 minutes at $4^{\circ} \mathrm{C}$. Total protein concentration was measured by the BCA protein assay, and $100 \mu \mathrm{g}$ of total protein was used to measure proteasome activity. The $20 \mathrm{~S}$ proteasome assay kit (EMD Millipore) was used according to manufacturer's instructions. The assay is based on detection of fluorophore 7-amino-4-methylcoumarin (AMC) after cleavage from the labeled substrate LLVYAMC. The free AMC fluorescence was quantified using 380-nm excitation and 460-nm emission filters.

\section{Histological Investigation}

Tissues used for histological investigation were fixed in $10 \%$ formalin, embedded in paraffin, and stained with $\mathrm{H}$ \& E. The antibody TRA-1-85/CD147 (RD Systems) was used to stain for human cells.

\section{Statistical Analysis}

Survival data were plotted using the Kaplan-Meier method. The end point analyzed was the number of days of survival, counted from the date on which tumor cells were implanted by intracranial injection. All 30 mice $(6$ per treatment group) died, and therefore standard methods for uncensored data could be used to compare the treatment groups. Prior to analysis, the end point (number of days surviving) was log-transformed to render the distribution of the data compatible with the assumptions of the normal distribution. The resulting means and confidence intervals were transformed back to the original scale. A 1-way ANOVA (with 5 treatment groups) was used for the overall test for differences. Once the overall F-test indicated that some of the means were different from the others $(p=0.004)$, then selected pairwise comparisons were performed using the Tukey method of adjusting for multiple comparisons. A statistical evaluation result of $p<0.05$ was considered significant.

\section{Results}

\section{Bortezomib Is Cytotoxic to Glioma Cells In Vitro}

To determine whether bortezomib is toxic for glioma cells in vitro, a series of glioma cell lines were treated with bortezomib, at doses ranging from 0 to $25 \mathrm{nM}$. After 48 hours of incubation, the results (Fig. 1) show that the median inhibitory concentrations (IC50) for the 3 cell

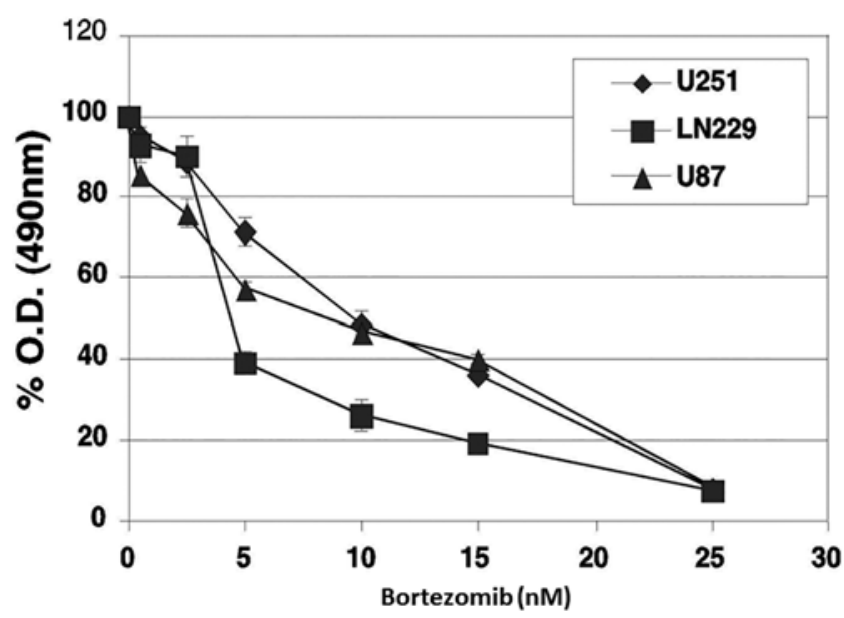

FIG. 1. Bortezomib is cytotoxic for human glioma cells in vitro. Glioma cells (U251, LN229, U87) were treated with bortezomib (0-25 nM) for 48 hours. Cell death was evaluated using the MTT assay. O.D. = optical density.

lines tested were similar, in the low nanomolar range of 5-10 nM.

\section{Bortezomib Is Effective in Delaying Tumor Growth in the Subcutaneous In Vivo Model}

To determine whether bortezomib is effective in vivo, the rodent subcutaneous tumor model was used. Tumor cells (U251) were implanted into the right flank. Once tumors were palpable (on approximately Day 15), bortezo$\mathrm{mib}(0.3 \mathrm{mg} / \mathrm{kg})$ was administered IV twice per week. The size of tumors was measured every 3-4 days. The results demonstrate that administration of bortezomib through the intravenous route was significantly effective in delaying tumor growth $(\mathrm{p}<0.02)$ (Fig. 2A).

To determine whether this response was observed with other glioma cell lines, and using another mode of drug delivery, U87 was tested; here bortezomib $(0.3 \mathrm{mg} / \mathrm{kg})$ was administered subcutaneously (Fig. 2B). The results show that in this subcutaneous model, bortezomib delayed tumor progression $(\mathrm{p}<0.01)$.

\section{Intravenous Bortezomib Is Not Effective in the In Vivo Orthotopic Intracranial Glioma Model}

To determine whether bortezomib can be useful for intracranial glioma therapy using a systemic mode of delivery, this drug was given IV in the orthotopic intracranial glioma model. The U251 glioma cells were implanted into athymic nude mice, and the survival end point was documented. The results (Fig. 3A) showed no significant differences in survival time between IV $(0.3 \mathrm{mg} / \mathrm{kg})$ bortezomib-treated animals as compared with the vehicle control. This experiment was repeated using the U87 line, with similar results (Fig. 3B).

\section{Bortezomib Is an Effective Drug for Intracranial Tumors When Delivered IT}

To determine whether the lack of response to bortezomib in the intracranial xenograft model was due to the inability of the drug to enter the brain, we used direct 

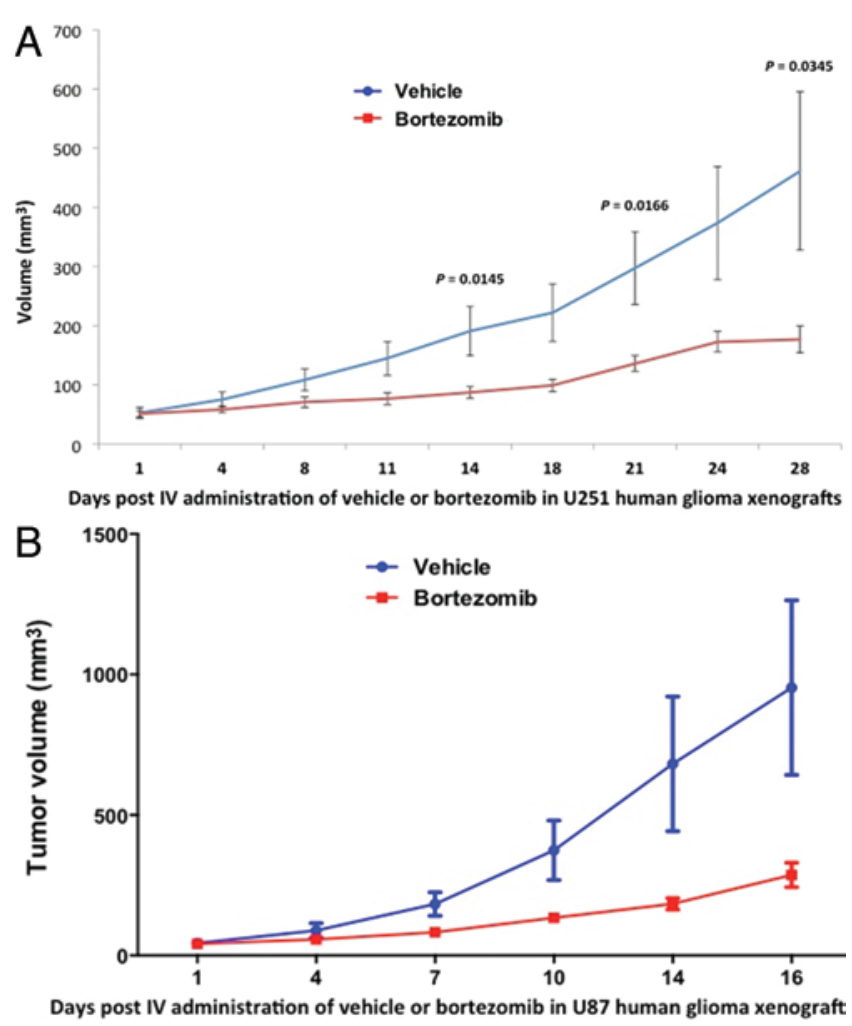

FIG. 2. Bortezomib decreased subcutaneous tumor progression when administered IV. A: Glioma cells (U251) were implanted subcutaneously into athymic nu/nu mice. Fourteen days later, intravenous treatment was initiated: vehicle treatment (blue); bortezomib (36 $\mu \mathrm{g}$ total) (red). Subsequently animals were left untreated for 14 days. Bortezomib treatment significantly $(p=0.0145)$ decreased tumor growth rate. B: Glioma cells (U87) were implanted subcutaneously in athymic nude mice. Bortezomib was administered at a total dose of $36 \mu \mathrm{g}$ by intravenous injection beginning on Day 30 postimplantation. Bortezomib significantly $(p=0.041)$ decreased tumor growth rate for subcutaneous tumors. Figure is available in color online only.

intratumoral delivery of bortezomib. In this procedure, 14-day-delivery Alzet mini-osmotic pumps were implanted into tumor-bearing mice. The pump was used because it is an efficient method for intratumoral administration and circumvents the BBB..$^{12,21}$ Furthermore, bortezomib was functioning as a proteasome inhibitor in the brain environment (Supplemental Fig. 1). The results (Fig. 4) show that for intratumoral delivery compared with intravenous $(36 \mu \mathrm{g})$ administration, lower intratumoral doses $(3.6 \mu \mathrm{g}$ and $1.2 \mu \mathrm{g})$ significantly enhanced survival $(\mathrm{p}=0.0022$ and $p=0.0005$, respectively). Intratumoral administration of bortezomib increased the median survival time from 23 days to 37 days, providing an approximately $40 \%$ increase in survival. Survival of the control animals that received vehicle and the intravenous administration groups were not statistically different. Tumor progression could not be determined using imaging because the pump interfered with imaging.

The doses of bortezomib used in these experiments were determined by injecting escalating doses of the drug intracerebrally (delivered by osmotic mini-pump) into normal, nontumor-bearing mice. Doses of $0.36 \mu \mathrm{g}$, $1.2 \mu \mathrm{g}$, and $3.6 \mu \mathrm{g}$ exhibited no toxicity, whereas doses
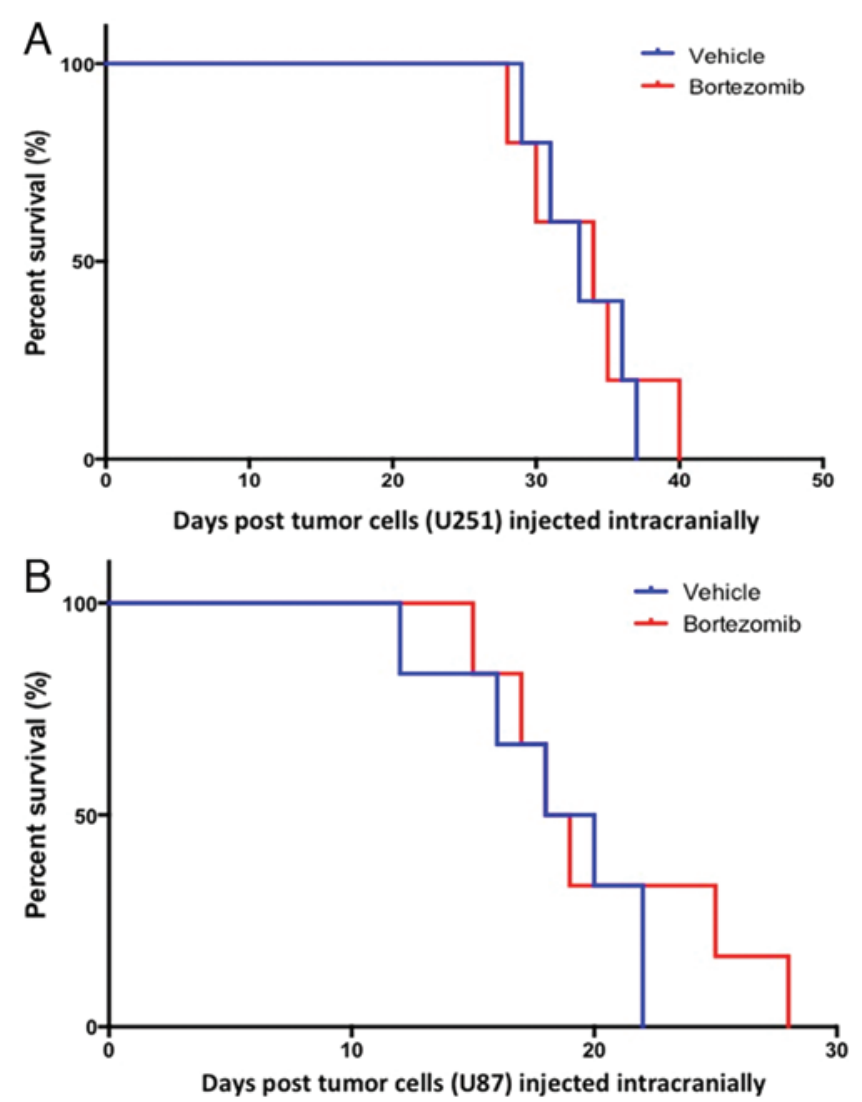

FIG. 3. Bortezomib does not affect intracranial tumor progression when delivered systemically. Human glioma cells U251 (A) or U87 (B) were implanted intracranially; subsequently, mice were given bortezomib (36 $\mu \mathrm{g}$ total) (red) or vehicle (blue) IV. The brain tumor size was monitored by optical imaging weekly, and animal survival data were analyzed by Kaplan-Meier plot. There were no significant differences between bortezomib compared with vehicle saline control. Figure is available in color online only.

at 7.2 $\mu \mathrm{g}, 18.0 \mu \mathrm{g}$, and $36.0 \mu \mathrm{g}$ were toxic and fatal to the testing animals. In Fig. 4 , treatment groups $(n=6)$ were vehicle (saline-filled pump); bortezomib given IV (36 $\mu \mathrm{g}$ in total); bortezomib IT (low dose, $0.36 \mu \mathrm{g}$ ); bortezomib IT (medium dose, $1.2 \mu \mathrm{g}$ ); and bortezomib IT (high dose, $3.6 \mu \mathrm{g})$. The median survival analysis showed that local administration of bortezomib significantly increased survival time from 23 days to 34 and 37 days for medium and high doses, respectively. The statistical analysis illustrated the $\mathrm{p}$ value significance as follows: bortezomib IV $(36 \mu \mathrm{g})$ versus bortezomib IT (medium dose, $1.2 \mu \mathrm{g}$ ), $\mathrm{p}=$ 0.0005 ; and bortezomib IV (36 $\mu \mathrm{g})$ versus bortezomib IT (high dose, $3.6 \mu \mathrm{g}$ ), $\mathrm{p}=0.0022$. By contrast, for vehicle versus bortezomib IV (36 $\mu \mathrm{g}), \mathrm{p}=0.9523$ (not significant); and for bortezomib IV (36 $\mu \mathrm{g}$ ) versus bortezomib IT (0.36 $\mu \mathrm{g}$, low dose), $\mathrm{p}=0.1104$ (not significant). The results for pump administration of the medium dose $(1.2 \mu \mathrm{g})$ and the high dose $(3.6 \mu \mathrm{g})$ of bortezomib were not significantly different, suggesting that the drug concentration may have reached a plateau. Thus, circumventing the BBB by direct intracranial administration of bortezomib is effective for increasing survival of animals bearing intracranial tumors. 


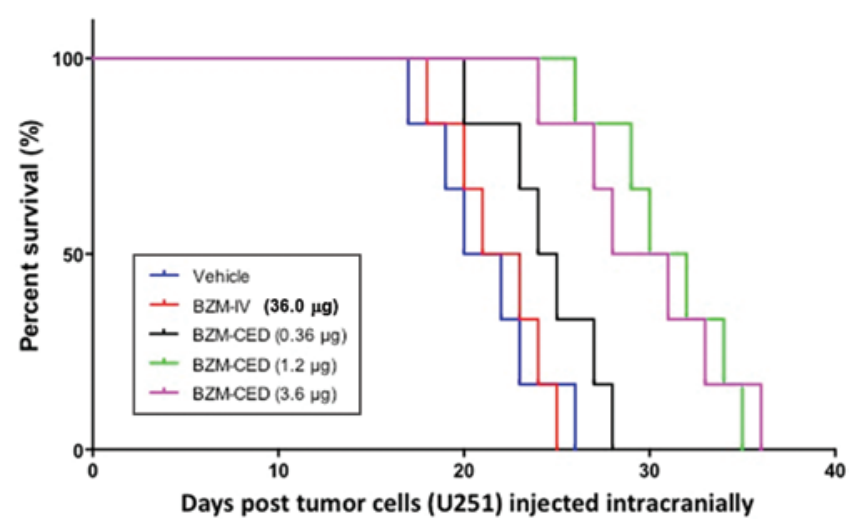

FIG. 4. Bortezomib (BZM) administered IT is effective in increasing survival. Glioma cells (U251) were implanted intracranially. After 10 days, animals were treated IT with vehicle; bortezomib IV ( $36 \mu \mathrm{g}$ total); bortezomib IT (low dose, $0.36 \mu \mathrm{g}$ total); bortezomib IT (medium dose, $1.2 \mu \mathrm{g}$ total); and bortezomib IT (high dose, $3.6 \mu \mathrm{g}$ total). Local administration of bortezomib delayed tumor progression and significantly increased median survival time (from 23 to 34 and 37 days for medium and high doses, respectively). Statistical analysis showed the $p$ values as follows: vehicle versus bortezomib IV ( $36 \mu \mathrm{g}$ total), $p=0.9523$ (not significant); bortezomib IV $(3.6 \mu \mathrm{g})$ versus bortezomib IT (low dose, $0.36 \mu \mathrm{g}$ total), $p=0.1104$ (not significant); bortezomib IV $(36 \mu \mathrm{g})$ versus bortezomib IT (medium dose, $1.2 \mu \mathrm{g}$ total), $p=0.0005$; and bortezomib IV $(36 \mu \mathrm{g})$ versus bortezomib IT (high dose, $3.6 \mu \mathrm{g}$ total), $p=0.0022$. CED $=$ convection-enhanced delivery. Figure is available in color online only.

\section{Discussion}

Effective treatment of GBM is still a challenge, and therefore new drugs and alternative methods of drug delivery must be considered. Bortezomib is a powerful cytotoxic agent, which is functional at nanomolar concentrations. We show here that this powerful agent is also effective against gliomas in vivo, but that the route of administration is critical for drug effectiveness. For intracranial tumors, bortezomib requires intracranial administration.

The requirement for local application of the drug became evident as a result of several in vivo experiments in which varying modes of drug administration were used. In the subcutaneous glioma model, where tumors were implanted into the flank and bortezomib was administered subcutaneously, bortezomib was effective in delaying tumor progression. However, the same dose of bortezomib (36 $\mu \mathrm{g}$ total) delivered subcutaneously to animals bearing an intracranial tumor was not effective. Only bortezomib administered intracranially reduced tumor growth, resulting in a significant increase in survival time. A Phase II trial using the combination of bortezomib and tamoxifen administered systemically to patients with malignant gliomas showed no therapeutic benefit. ${ }^{14}$ Based on these and other pharmacokinetic studies, ${ }^{23}$ those authors suggest that the $\mathrm{BBB}$ may be responsible for the poor penetration of bortezomib into the tumor. Thus, the key to bortezomib activity is bypassing the BBB by direct intracranial administration of the drug. This mode of bortezomib administration is optimal for intracranial tumors.

Bortezomib in combination with other agents has been shown to enhance the drugs' activity in vitro. Bortezomib together with the histone deacetylase inhibitor vorinostat is effective in increasing apoptosis through activating mitochondria in vitro. ${ }^{18}$ This drug combination was also tested in vivo in a Phase II clinical trial for treatment of GBM. ${ }^{8}$ Bortezomib was administered IV. The trial results demonstrated no benefit, once again showing that systemic delivery of bortezomib is not effective for intracranial tumors. These data and our results indicate that bortezomib should not be used clinically unless the BBB is circumvented.

Previous studies have shown that bortezomib is cytotoxic for glioma stem cells, whereas it is not toxic to normal stem cells. ${ }^{9}$ The reason for this dichotomy is not clear. A possible explanation may be the result of differences in metabolism and functional levels of proteasomes in glioma stem cells compared with normal stem cells, thus contributing to the increased sensitivity of glioma stem cells. Reports have also indicated that bortezomib, at higher doses, has proangiogenic properties mediated by increased hypoxia-inducible factor- $1 \alpha$ and vascular endothelial growth factor. ${ }^{4}$ Our in vivo studies showed that microvessel densities in bortezomib-treated animals versus vehicle-treated mice were not significantly different (data not shown). A histological examination of the tissues noted that at Day 5 the tumor in IV treated animals (36 $\mu \mathrm{g}$ total) was larger, as compared with IT treated animals at the higher dose (3.6 $\mu \mathrm{g}$ total). Furthermore, staining these tissues with anti-human cell antibody (TRA 1-85) showed that intravenous treatment resulted in greater tumor cell invasion into mouse brain, compared with IT treated animals. These studies suggest that intratumoral delivery of bortezomib was more effective in reducing tumor progression than intravenous delivery (Supplemental Fig. 2).

Intracranial administration of bortezomib is effective because it circumvents the BBB. In this study intracranial drug delivery was used, providing direct access to the brain tumor. The mini-osmotic pump provides drug treatment directly to the brain and also bypasses the liver, thereby achieving the desired drug concentration in the glioma microenvironment while avoiding the use of high drug doses. Other mechanisms of direct drug administration may also be used. Gliadel wafers are FDA approved, and have been shown to be an effective method of local drug administration. ${ }^{7}$ The Ommaya reservoir has also been used for intratumoral drug delivery. ${ }^{16,17}$ Recently we have demonstrated that an implanted piezoelectric pump can be used in a leptomeningeal carcinomatosis model. ${ }^{6}$ Thus, bypassing the BBB is critical and may be accomplished by several techniques.

\section{Conclusions}

These studies demonstrate that bortezomib can be an effective therapy for the treatment of GBM, as long as the drug is administered in such a way that the BBB is circumvented. Using direct intratumoral delivery via an external pump or an implanted pump ${ }^{6}$ that will deliver directly to the brain tumor will make bortezomib an effective treatment for gliomas. Our data imply that future clinical studies should not be performed using bortezomib delivered IV for treatment of brain tumors because of the inability of the drug to penetrate the $\mathrm{BBB}$. Our data reveal that circumventing the BBB obstacle via direct local delivery IT 
is a feasible approach to exploit the therapeutic potential of bortezomib against GBM. Thus, alternative methods of bortezomib delivery can result in increased treatment options for GBM.

\section{References}

1. Adams J, Palombella VJ, Elliott PJ: Proteasome inhibition: a new strategy in cancer treatment. Invest New Drugs 18:109121,2000

2. Agnihotri S, Burrell KE, Wolf A, Jalali S, Hawkins C, Rutka JT, et al: Glioblastoma, a brief review of history, molecular genetics, animal models and novel therapeutic strategies. Arch Immunol Ther Exp (Warsz) 61:25-41, 2013

3. Boccadoro M, Morgan G, Cavenagh J: Preclinical evaluation of the proteasome inhibitor bortezomib in cancer therapy. Cancer Cell Int 5:18, 2005

4. Bota DA, Alexandru D, Keir ST, Bigner D, Vredenburgh J, Friedman HS: Proteasome inhibition with bortezomib induces cell death in GBM stem-like cells and temozolomideresistant glioma cell lines, but stimulates GBM stem-like cells' VEGF production and angiogenesis. J Neurosurg 119:1415-1423, 2013

5. Buac D, Shen M, Schmitt S, Kona FR, Deshmukh R, Zhang Z, et al: From bortezomib to other inhibitors of the proteasome and beyond. Curr Pharm Des 19:4025-4038, 2013

6. Chen TC, Napolitano GR, Adell F, Schönthal AH, Shachar Y: Development of the Metronomic Biofeedback Pump for leptomeningeal carcinomatosis: technical note. J Neurosurg 123:362-372, 2015

7. Dörner L, Ulmer S, Rohr A, Mehdorn HM, Nabavi A: Spaceoccupying cyst development in the resection cavity of malignant gliomas following Gliadel implantation-incidence, therapeutic strategies, and outcome. J Clin Neurosci 18:347-351, 2011

8. Friday BB, Anderson SK, Buckner J, Yu C, Giannini C, Geoffroy F, et al: Phase II trial of vorinostat in combination with bortezomib in recurrent glioblastoma: a north central cancer treatment group study. Neuro Oncol 14:215-221, 2012

9. Gong X, Schwartz PH, Linskey ME, Bota DA: Neural stem/ progenitors and glioma stem-like cells have differential sensitivity to chemotherapy. Neurology 76:1126-1134, 2011

10. Hideshima T, Mitsiades C, Akiyama M, Hayashi T, Chauhan D, Richardson P, et al: Molecular mechanisms mediating antimyeloma activity of proteasome inhibitor PS-341. Blood 101:1530-1534, 2003

11. Kahana S, Finniss S, Cazacu S, Xiang C, Lee HK, Brodie S, et al: Proteasome inhibitors sensitize glioma cells and glioma stem cells to TRAIL-induced apoptosis by PKCE-dependent downregulation of AKT and XIAP expressions. Cell Signal 23:1348-1357, 2011

12. Kawakami K, Kawakami M, Kioi M, Husain SR, Puri RK: Distribution kinetics of targeted cytotoxin in glioma by bolus or convection-enhanced delivery in a murine model. J Neurosurg 101:1004-1011, 2004

13. Ling YH, Liebes L, Ng B, Buckley M, Elliott PJ, Adams J, et al: PS-341, a novel proteasome inhibitor, induces Bcl-2 phosphorylation and cleavage in association with G2-M phase arrest and apoptosis. Mol Cancer Ther 1:841-849, 2002

14. Odia Y, Kreisl TN, Aregawi D, Innis EK, Fine HA: A phase II trial of tamoxifen and bortezomib in patients with recurrent malignant gliomas. J Neurooncol 125:191-195, 2015

15. Omuro AM, Faivre S, Raymond E: Lessons learned in the development of targeted therapy for malignant gliomas. Mol Cancer Ther 6:1909-1919, 2007

16. Oshiro S, Tsugu H, Komatsu F, Ohnishi H, Ueno Y, Saka- moto S, et al: Evaluation of intratumoral administration of tumor necrosis factor-alpha in patients with malignant glioma. Anticancer Res 26 (6A):4027-4032, 2006

17. Patchell RA, Regine WF, Ashton P, Tibbs PA, Wilson D, Shappley D, et al: A phase I trial of continuously infused intratumoral bleomycin for the treatment of recurrent glioblastoma multiforme. J Neurooncol 60:37-42, 2002

18. Premkumar DR, Jane EP, Agostino NR, DiDomenico JD, Pollack IF: Bortezomib-induced sensitization of malignant human glioma cells to vorinostat-induced apoptosis depends on reactive oxygen species production, mitochondrial dysfunction, Noxa upregulation, Mcl-1 cleavage, and DNA damage. Mol Carcinog 52:118-133, 2013

19. Richardson PG, Mitsiades C, Schlossman R, Ghobrial I, Hideshima T, Munshi N, et al: Bortezomib in the front-line treatment of multiple myeloma. Expert Rev Anticancer Ther 8:1053-1072, 2008

20. Seol DW: p53-Independent up-regulation of a TRAIL receptor DR 5 by proteasome inhibitors: a mechanism for proteasome inhibitor-enhanced TRAIL-induced apoptosis. Biochem Biophys Res Commun 416:222-225, 2011

21. van der Bom IM, Moser RP, Gao G, Sena-Esteves M, Aronin N, Gounis MJ: Frameless multimodal image guidance of localized convection-enhanced delivery of therapeutics in the brain. J Neurointerv Surg 5:69-72, 2013

22. Veringa SJ, Biesmans D, van Vuurden DG, Jansen MH, Wedekind LE, Horsman I, et al: In vitro drug response and efflux transporters associated with drug resistance in pediatric high grade glioma and diffuse intrinsic pontine glioma. PLoS One 8:e61512, 2013

23. Williamson MJ, Silva MD, Terkelsen J, Robertson R, Yu $\mathrm{L}, \mathrm{Xia} \mathrm{C}$, et al: The relationship among tumor architecture, pharmacokinetics, pharmacodynamics, and efficacy of bortezomib in mouse xenograft models. Mol Cancer Ther 8:3234-3243, 2009

24. Yang Y, Yu X: Regulation of apoptosis: the ubiquitous way. FASEB J 17:790-799, 2003

25. Zhang Y, Zhu X, Hou K, Zhao J, Han Z, Zhang X: Mcl-1 downregulation sensitizes glioma to bortezomib-induced apoptosis. Oncol Rep 33:2277-2284, 2015

\section{Disclosures}

Dr. Chen discloses ownership in Cognos Therapeutics. This work was sponsored and funded by Pharmaco-kinesis, Inc.

\section{Author Contributions}

Conception and design: Chen, Schönthal, Hofman. Acquisition of data: Wang, Cho, Rosenstein-Sisson, Marín Ramos, Price. Analysis and interpretation of data: Chen, Wang, Hurth, Hofman. Drafting the article: Chen, Rosenstein-Sisson, Marín Ramos, Schönthal, Hofman. Administrative/technical/material support: Chen. Study supervision: Chen, Hofman.

\section{Supplemental Information Online-Only Content}

Supplemental material is available with the online version of the article.

Supplemental Figs. 1 and 2. https://thejns.org/doi/suppl/10. 3171/2016.11.JNS161212.

\section{Correspondence}

Thomas C. Chen, Departments of Neurosurgery and Pathology, University of Southern California, 2011 Zonal Ave., Los Angeles, CA 90033. email: thomas.chen@med.usc.edu. 